Research

\title{
The infralimbic cortex regulates the consolidation of extinction after cocaine self-administration
}

\author{
Ryan T. LaLumiere, ${ }^{1}$ Kate E. Niehoff, and Peter W. Kalivas \\ Neurobiology of Addiction Research Center, Department of Neurosciences, Medical University of South Carolina, Charleston, \\ South Carolina 29425, USA
}

\begin{abstract}
The infralimbic cortex (IL) regulates the consolidation of extinction learning for fear conditioning. Whether the IL influences the consolidation of extinction learning for cocaine self-administration is unknown. To address this issue, male Sprague-Dawley rats underwent 2 wk of cocaine self-administration followed by extinction training. On the first $5 \mathrm{~d}$ of extinction, rats underwent brief (15- or 30-min) extinction sessions and received intra-IL microinjections immediately after each extinction session. On days 6-12 of extinction, rats underwent full-length (2-h) extinction sessions that were used to assess the retention of the extinction learning from the short sessions. IL inactivation via microinjections of the GABA agonists baclofen and muscimol (BM) immediately after the extinction sessions (days 1-5) impaired the retention of extinction learning. Control experiments demonstrated that this effect was not due to inactivation of the prelimbic cortex or due to effects of the drugs on the subsequent day's behavior. In contrast, post-training intra-IL microinjections of the allosteric AMPA receptor potentiator 4-[2-(phenylsulfonylamino)ethylthio]-2,6-difluorophenoxyacetamide (PEPA) enhanced retention of the extinction learning. As evidence suggests a role for the $\beta$-adrenergic receptors in memory consolidation, other rats received microinjections of the $\beta_{2}$-adrenergic receptor agonist clenbuterol or antagonist $\mathrm{ICl}-118,551$ (ICl). Post-training intra-IL administration of clenbuterol or pre-training administration of ICl enhanced or impaired, respectively, the retention of extinction learning. These data indicate that the IL, and specifically the glutamatergic and $\beta$-adrenergic systems in the IL, regulates the consolidation of extinction of cocaine self-administration and that the IL can be manipulated to influence the retention of extinction.
\end{abstract}

[Supplemental material is available online at http://www.learnmem.org.]

Previous findings have shown that the infralimbic cortex (IL), the ventral portion of the medial prefrontal cortex (mPFC), regulates the extinction of tone fear conditioning. IL lesions impair the consolidation of extinction of tone fear conditioning (Quirk et al. 2000; Morgan et al. 2003; Lebron et al. 2004), as well as the extinction of trace eyeblink conditioning (Weible et al. 2000) and Pavlovian appetitive conditioning (Rhodes and Killcross 2004, 2007). During an extinction session for tone fear conditioning, electrical stimulation of the IL paired with presentation of the previously conditioned tones reduces freezing in rats (Milad and Quirk 2002). Moreover, when the rats are presented with the tones on a subsequent day, the rats also show reduced freezing, indicating that the IL stimulation paired with tones enhanced retention of the extinction learning. In contrast, activity in the prelimbic cortex (PL), the more dorsal region of the mPFC, appears to promote the expression of fear (Vidal-Gonzalez et al. 2006; Burgos-Robles et al. 2009), suggesting that the IL and PL oppositely regulate behavioral responses to the conditioned tone.

Electrophysiological recordings from the IL have shown that extinction for tone fear conditioning enhances intrinsic excitability in IL neurons, as reflected in increased burst spiking in these neurons (Santini et al. 2008). Post-training N-methyl-D-aspartate (NMDA) receptor blockade in the IL reduces burst firing in the IL and impairs consolidation of extinction (Burgos-Robles et al. 2007). Moreover, the degree of IL burst spiking immediately after an extinction session correlates with recall of extinction during a

\footnotetext{
${ }^{1}$ Corresponding author.
}

Email lalumie@musc.edu; fax (843) 792-4423.

Article is online at http://www.learnmem.org/cgi/doi/10.1101/lm.1576810. subsequent session (Burgos-Robles et al. 2007), indicating that extinction training induces activity-dependent changes in the IL that, in turn, influence the later expression of the extinction. Intra-mPFC microinjections of the AMPA receptor potentiator 4-[2-(phenylsulfonylamino)ethylthio]-2,6-difluorophenoxyacetamide (PEPA) enhance extinction of contextual fear conditioning (Zushida et al. 2007). These findings strongly suggest that, for fear conditioning, the IL is involved in the consolidation of extinction learning as well as in the expression of extinction.

As in fear conditioning, the mPFC regulates the expression of the learned behavior for drug self-administration (McFarland and Kalivas 2001; McLaughlin and See 2003; Rebec and Sun 2005). Considerable work has identified the PL as a critical locus in the reinstatement of drug-seeking behavior in rats. Inactivation of the PL with the GABA agonists baclofen and muscimol prevents cue or drug-prime reinstatement for cocaine (McFarland and Kalivas 2001; McLaughlin and See 2003; McFarland et al. 2004) or heroin (LaLumiere and Kalivas 2008; Rogers et al. 2008) seeking. Moreover, stimulation of the PL with dopamine receptor agonists promotes drug-seeking behavior in rats (McFarland and Kalivas 2001; Park et al. 2002). In the standard reinstatement paradigm, rats undergo extinction training after drug selfadministration. Recently, Peters et al. (2008) demonstrated that, after extinction training for cocaine self-administration, IL inactivation increases drug-seeking behavior, suggesting that IL activity is critical for suppressing the expression of the original memory (i.e., the drug-seeking behavior).

Although these findings identified a role for the IL in the expression of extinction learning for cocaine self-administration, they did not determine whether, as with extinction of tone fear conditioning (see above), the IL modulates memory 
consolidation of the extinction learning. Therefore, the present experiments investigated this issue. Rats underwent cocaine selfadministration followed by extinction training. During the first $5 \mathrm{~d}$ of extinction training, rats received intra-IL microinjections immediately after each session to assess whether the IL influences the consolidation of extinction in this paradigm. In the first experiment, rats received microinjections of the GABA agonists baclofen and muscimol (BM) to inactivate the IL immediately after each extinction session. As recent findings have shown that the glutamatergic (Burgos-Robles et al. 2007; Zushida et al. 2007) and noradrenergic (Mueller et al. 2008) systems in the IL influence the consolidation of extinction for fear conditioning, the present experiments investigated these systems in the cocaine self-administration extinction paradigm. Rats received microinjections of the AMPA receptor potentiator PEPA, while other rats received microinjections of the $\beta_{2}$-adrenergic receptor agonist clenbuterol or antagonist ICI-118,551 (ICI).

\section{Results}

\section{Experiment 1. Post-training baclofen/muscimol (BM) microinjections into the IL impair retention of extinction}

To assess whether IL activity is necessary for normal memory consolidation of extinction after cocaine self-administration, rats underwent extinction training for $12 \mathrm{~d}$. On days $1-5$, rats underwent 30-min extinction sessions and received intra-IL microinjections of the GABA-B and -A agonists baclofen and muscimol (BM), respectively, immediately after each extinction session to inactivate the IL. The sessions were $30 \mathrm{~min}$ in length, rather than the full $2 \mathrm{~h}$ as with self-administration, because evidence suggests that manipulations made further in time after learning are less likely to influence consolidation (Duncan 1949; McGaugh 1966; Burgos-Robles et al. 2007). On days 6-12, rats underwent 2 -h extinction sessions with no microinjections in order to assess the retention of the earlier extinction learning. There were no significant differences in infusions (means \pm SEM for vehicle group: $33 \pm 1.8$; BM group: $34 \pm 2.1 ; t_{(15)}=$ $0.48, P>0.05$ ) or active lever presses (means \pm SEM for vehicle: $46 \pm 6.7$; BM group: $\left.68 \pm 15 ; t_{(15)}=1.4, P>0.05\right)$ between the groups averaged across the last $3 \mathrm{~d}$ of self-administration. Figure $1 \mathrm{~A}$ shows the active lever presses during extinction on days 1-5 (30-min sessions) and, after the line break, days 6-12 (2-h sessions). For days $1-5$ of extinction, a two-way repeatedmeasures analyses of variance (ANOVA) found a significant effect of time $\left(F_{(4,60)}=7.736, P<0.0001\right)$ but no interaction $(P>0.05)$ or effect of group $(P>0.05)$. For days $6-12$ of extinction, a twoway repeated-measures ANOVA revealed a significant effect of time $\left(F_{(6,90)}=5.513, P<0.0001\right)$, a significant effect of group $\left(F_{(1,90)}=6.884, P<0.05\right)$, and no interaction $(P>0.05)$. On days $6-12$ of extinction training, rats that had received posttraining intra-IL BM microinjections on days 1-5 had impaired retention of the extinction learning, as indicated by the increased active lever pressing. Figure $1 \mathrm{~A}$ also shows the total active lever presses over the first $30 \mathrm{~min}$ of the extinction session on day 6 . The two groups showed only a trend toward a significant difference in the first $30 \mathrm{~min}\left(t_{(15)}=1.943, P<0.1\right)$.

To determine whether the effects of IL inactivation were due to spread along the microinjection track into the PL, rats underwent identical self-administration and training as in Figure 1A but received $\mathrm{BM}$ microinjections into the PL immediately after each extinction session on days $1-5$. There were no significant differences in infusions (means \pm SEM for vehicle: $33.7 \pm 2.2$; BM group: $\left.36.2 \pm 2.2 ; t_{(9)}=0.8668, P>0.05\right)$ or active lever presses (means \pm SEM for vehicle: $45.8 \pm 2.6$; BM group: $52.2 \pm 9.2$; $\left.t_{(9)}=0.6174, P>0.05\right)$ between the groups averaged across the last $3 \mathrm{~d}$ of self-administration. Figure $1 \mathrm{~B}$ shows the active lever presses of rats that had received $\mathrm{BM}$ or vehicle microinjections into the PL immediately after extinction training on the first $5 \mathrm{~d}$ of extinction. There were no significant effects of time, group, or the interaction on days $1-5$ or days $6-12$ ( $P>0.05$ in all cases). $\mathrm{BM}$ microinjections into the PL did not affect retention of the extinction learning, indicating that the memory-influencing effects of BM microinjections were limited to microinjections in the IL.

To demonstrate the time-limited nature of consolidation, as well as to determine whether the inactivation was affecting the subsequent extinction session $1 \mathrm{~d}$ later rather than the consolidation of the prior session, rats underwent identical selfadministration and extinction training as in Figure $1 \mathrm{~A}$ but received their BM microinjections into the IL $3 \mathrm{~h}$ after the end of the extinction session. There were no significant differences in infusions (means \pm SEM for vehicle: $32.1 \pm 3.5$; BM group: $36.7 \pm 6 ; t_{(11)}=0.6301, P>0.05$ ) or active lever presses (means \pm SEM for vehicle: $65 \pm 19$; BM group: $92 \pm 38$; $t_{(11)}=0.545, P$ $>0.05$ ) between the groups averaged across the last $3 \mathrm{~d}$ of selfadministration. Figure $1 \mathrm{C}$ shows the active lever presses of rats that had received microinjections of $\mathrm{BM}$ or vehicle into the IL $3 \mathrm{~h}$ after the end of the extinction session. There were no significant effects of time, group, or the interaction on days 1-5 or days 6-12 ( $P>0.05$ in all cases). Thus, intra-IL BM microinjections given $3 \mathrm{~h}$ after training had no effect on the rats' retention of the extinction learning, indicating that the memory-influencing effects of BM microinjections were limited to the time immediately after extinction training.

\section{Experiment 2. Post-training PEPA microinjections into the IL enhance retention of extinction learning}

To determine whether activation of IL glutamatergic receptors enhances the consolidation of extinction, rats underwent self-administration and extinction training and received intraIL microinjections of the AMPA receptor potentiator 4[2-(phenylsulfonylamino)ethylthio]-2,6-difluorophenoxyacetamide (PEPA) immediately after extinction sessions on days 1-5. There were no significant differences in infusions (means \pm SEM for vehicle: $40 \pm 6.3$; PEPA group: $36.1 \pm 7.2 ; t_{(11)}=0.4045, P>$ 0.05 ) or active lever presses (means \pm SEM for vehicle: $108.3 \pm$ 50.7; PEPA group: $\left.114 \pm 68.7 ; t_{(11)}=0.07417, P>0.05\right)$ between the groups, averaged across the last $3 \mathrm{~d}$ of self-administration. Figure 2 shows the active lever presses during extinction of rats that received intra-IL microinjections of PEPA or vehicle immediately after extinction training sessions on days 1-5. Extinction sessions on days $1-5$ were $15 \mathrm{~min}$ in length in order to reduce the extinction learning in the control animals and, thus, enable enhanced retention to be observed. For the $15 \mathrm{~min}$ extinction sessions on days $1-5$, a two-way repeated-measures ANOVA found a significant interaction $\left(F_{(4,44)}=3.319, P<0.05\right)$, a significant effect of group $\left(F_{(1,44)}=6.249, P<0.05\right)$, and no effect of time $(P>0.05)$. Post-hoc least significant difference (LSD) tests revealed that those rats receiving PEPA had significantly fewer active lever presses on days 4 and 5 of extinction $(P<$ $0.05)$. For the 2 h extinction sessions on days $6-12$, there was a significant interaction $\left(F_{(6,66)}=4.489, P<0.001\right)$, a significant effect of time $\left(F_{(6,66)}=29.48, P<0.0001\right)$, and a significant effect of group $\left(F_{(1,66)}=23.89, P<0.001\right)$. Post-hoc LSD tests revealed that that those rats receiving PEPA had significantly fewer active lever presses on day 6 of extinction $(P<0.01)$. Thus, rats that received PEPA showed decreased active lever pressing on days 1-5 and on days 6-12 compared with vehicle-control rats, reflecting enhanced retention of extinction learning. 


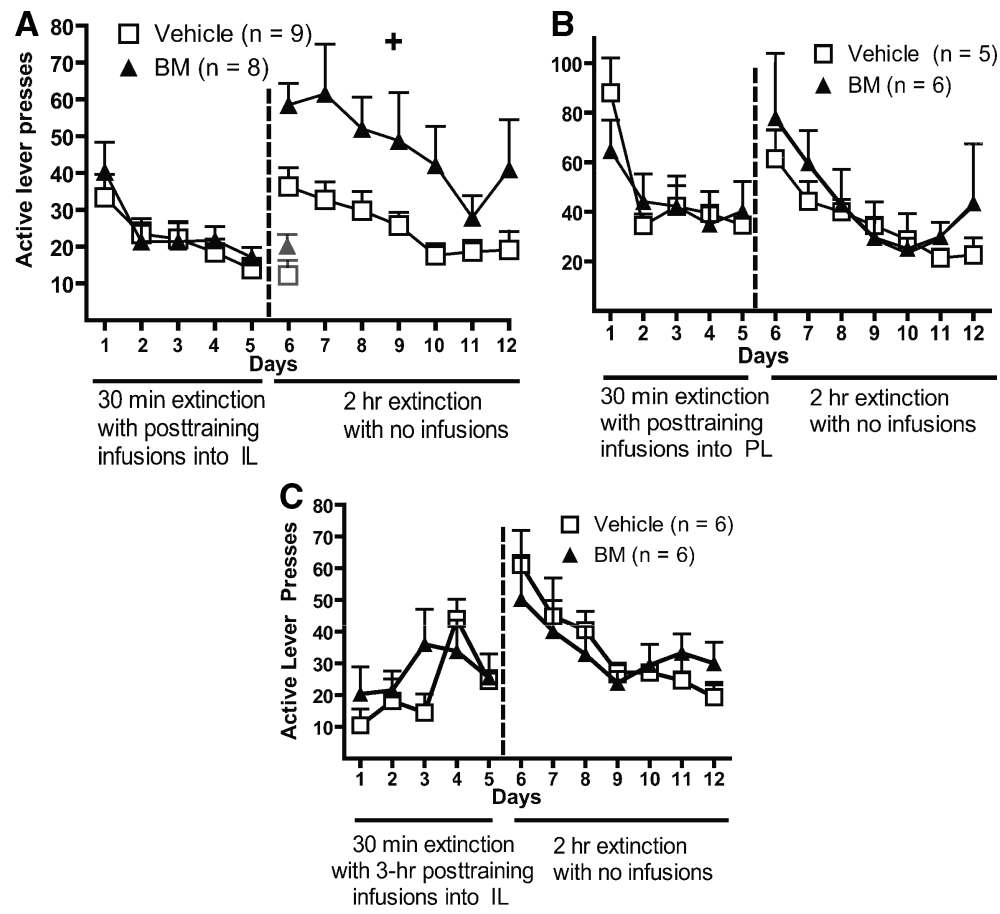

Figure 1. Impaired retention of extinction in rats that received intra-IL microinjections of baclofen/ muscimol (BM) on days 1-5 of extinction. (A) Active lever presses on days 1-12 of extinction training in which rats received BM into the IL immediately after 30-min extinction sessions on days $1-5$. Days $1-$ 5 were $30 \mathrm{~min}$ in length, and days $6-12$ were $2 \mathrm{~h}$ in length. The faded symbols on day 6 indicate the first 30 min of that session. (+) $P<0.05$ for overall group difference for days $6-12$. (B) Active lever presses on days $1-12$ of extinction training in which rats received $B M$ microinjections into the PL on days 1-5 (30-min session length). There were no significant effects of time, group, or the interaction on days $1-5$ or days $6-12$. (C) Active lever presses on days $1-12$ of extinction training in which rats received intra-IL BM microinjections $3 \mathrm{~h}$ after the training session on days 1-5 (30-min session length). There were no significant effects of time, group, or the interaction on days $1-5$ or days $6-12$.

\section{Experiment 3. Post-training clenbuterol microinjections into the IL enhance retention of extinction learning}

To determine whether $\beta_{2}$-adrenergic receptor activation in the IL enhances extinction consolidation, rats received microinjections of the $\beta$-adrenergic receptor agonist clenbuterol immediately after extinction sessions on days 1-5 (15-min session length). There were no significant differences in infusions (means \pm SEM for vehicle: $34.3 \pm 2.1$; clen-3: $36.4 \pm 2.0$; clen-10: $\left.37.6 \pm 3.1 ; F_{(2,28)}=0.4096, P>0.05\right)$ or active lever presses (means \pm SEM for vehicle: $58.3 \pm 14.5$; clen-3: $70.4 \pm 20.4$; clen-10: $\left.69.6 \pm 12.8 ; F_{(2,28)}=0.1267, P>0.05\right)$ between the groups averaged across the last $3 \mathrm{~d}$ of self-administration. Figure 3A shows the active lever presses during extinction of rats that received intra-IL microinjections of the $\beta_{2}$-adrenergic agonist clenbuterol immediately after extinction training sessions on days $1-5$. For the 15-min extinction sessions on days 1-5, a two-way ANOVA found no significant interaction $\left(F_{(8,112)}=0.7881, P>0.05\right)$, no effect of group $\left(F_{(2,112)}=2.081\right.$, $P>0.05)$, and no effect of time $\left(F_{(4,112)}=1.891, P>0.05\right)$. For the 2-h extinction sessions on days 6-12, a two-way ANOVA found a significant interaction $\left(F_{(12,168)}=2.39, P<0.01\right)$, a trend toward an effect of group $\left(F_{(2,168)}=2.637, P<0.09\right)$, and a significant effect of time $\left(F_{(6,168)}=44.14, P<0.0001\right)$. Post-hoc LSD tests indicated that those rats that received either dose of clenbuterol (3 or $10 \mathrm{ng}$ ) had significantly lower levels of active lever pressing on day 6 of extinction compared with vehicle controls $(P<0.05)$.
Experiment 4. Pre-training, but not post-training, $\beta_{2}$-adrenergic antagonist $\mathrm{ICl}$ microinjections into the IL impair retention of extinction learning

To determine whether $\beta_{2}$-adrenergic receptor blockade in the IL enhances extinction consolidation, rats received microinjections of the $\beta_{2}$-adrenergic receptor antagonist ICI immediately before or after extinction sessions on days 1-5 (30-min session length). There were no significant differences across the last $3 \mathrm{~d}$ of self-administration in infusions (means \pm SEM for vehicle: $37.9 \pm$ 4.7; ICI: $32.8 \pm 1.6 ; t_{(8)}=0.8496, P>$ $0.05)$ or average active lever presses (means \pm SEM for vehicle: $79.8 \pm 31.9$; ICI: $\left.40.5 \pm 2.5 ; t_{(8)}=0.9849, P>0.05\right)$ between the groups that received posttraining microinjections, and no differences in average infusions (means \pm SEM for vehicle: $32.4 \pm 3.4$; ICI: $30.6 \pm$ $1.9 ; t_{(9)}=0.5226, P>0.05$ ) or active lever presses (means \pm SEM for vehicle: 46.7 \pm 8.5 ; ICI: $49.0 \pm 9.6 ; t_{(9)}=0.1590, P$ $>0.05$ ) between the groups that received pre-training microinjections. Figure $3 \mathrm{~B}$ and $\mathrm{C}$, shows the active lever presses during extinction days $1-12$ for rats receiving ICI microinjections into the IL. Figure $3 \mathrm{~B}$ shows that ICI microinjections given immediately after extinction sessions (30 min) on days $1-5$ had no effect on retention of the extinction learning. For the 30-min extinction sessions on days $1-5$, a two-way repeated-measures ANOVA found a significant effect of time $\left(F_{(4,36)}=11.42, P<\right.$ $0.0001)$ but no effect of group $(P>0.05)$ or interaction $(P>$ $0.05)$. For the 2 -h extinction sessions on days $6-12$, a two-way repeated-measures ANOVA found a significant effect of time $\left(F_{(6,54)}=14.44, P<0.0001\right)$ and no interaction or effect of group $(P>0.05)$. In contrast, Figure $3 \mathrm{C}$ shows that ICI microinjections given immediately prior to extinction sessions $(30 \mathrm{~min})$ on days 1-5 impaired retention of the extinction learning, as assessed

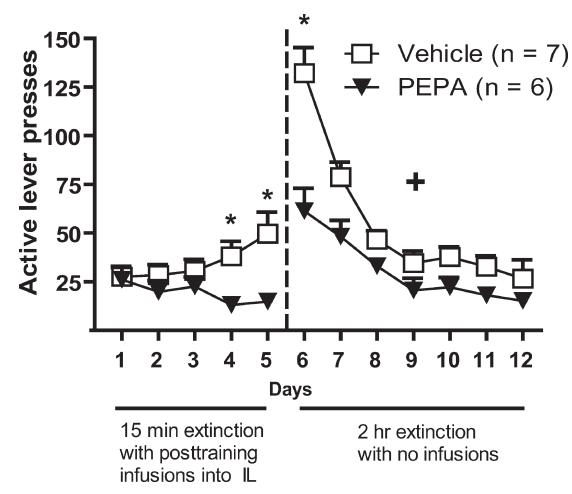

Figure 2. Enhanced retention of extinction of rats that received intra-IL microinjections of the AMPA receptor potentiator PEPA after 15 min extinction sessions on days $1-5 .\left(^{*}\right) P<0.05$ for post-hoc difference between the groups on that day, $(+) P<0.05$ for overall group difference. 


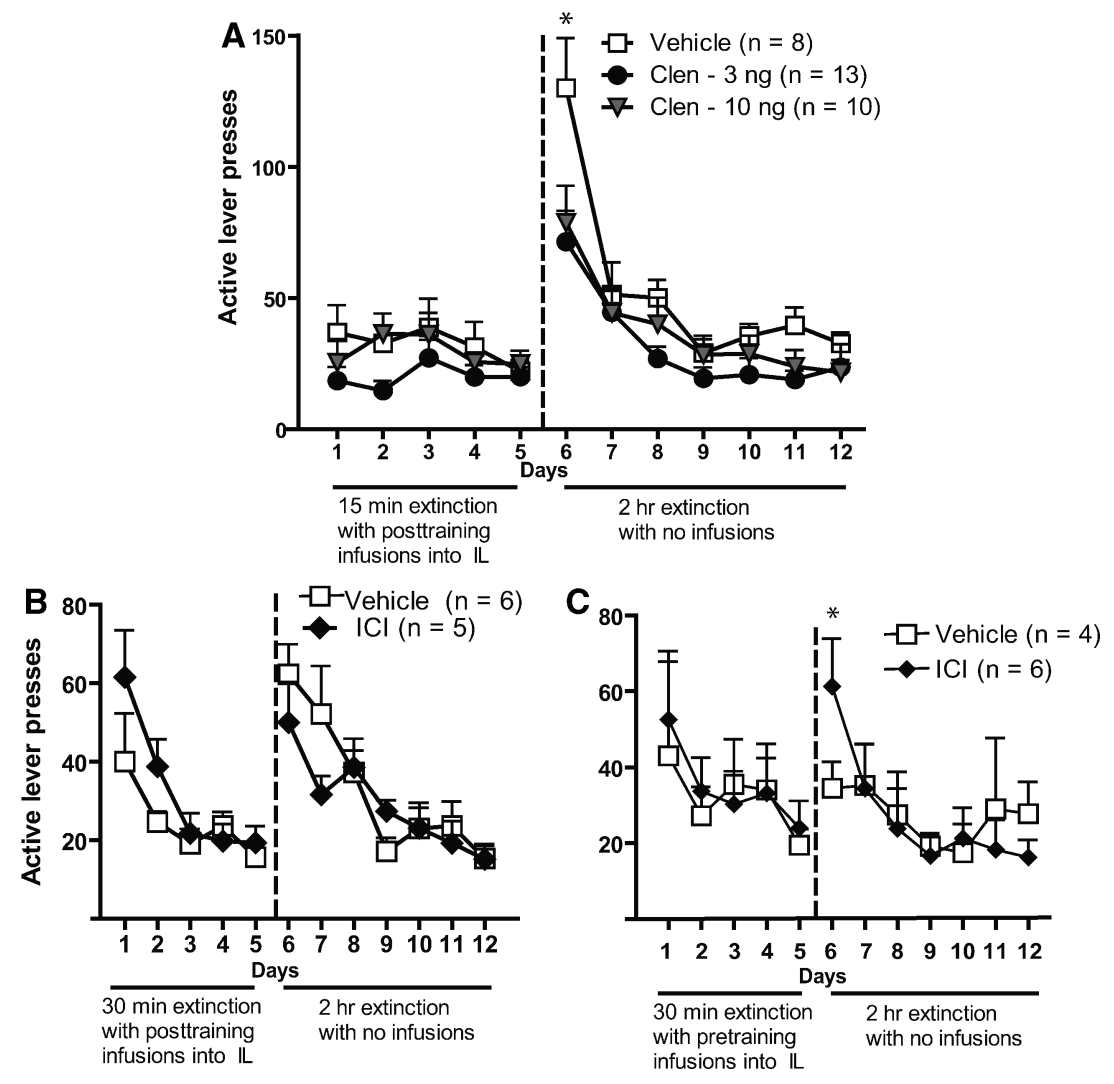

Figure 3. $\beta$-adrenergic receptor activation enhances, whereas receptor blockade impairs, the retention of extinction. (A) Active lever presses across days $1-12$ of extinction for those rats receiving intra-IL microinjections of the $\beta$-adrenergic receptor agonist clenbuterol immediately after training on days $1-5$ (15-min session length). (B) Active lever presses on days 1-12 of extinction for those rats that received intra-IL microinjections of ICl immediately after each extinction session on days 1-5 (30-min session length). (C) Active lever presses on days 1-12 of extinction for those rats that received intra-IL microinjections of $\mathrm{ICl}$ immediately prior to each extinction session on days $1-5$ (30-min session length). $\left.{ }^{*}\right) P$ $<0.05$, for significant difference on that day between vehicle-control rats and rats that received either dose of clenbuterol or between vehicle-control rats and rats that received $\mathrm{ICI}$.

by active lever presses on day 6 . For days $1-5$ of extinction, a two-way repeated-measures ANOVA found no significant effects $(P>0.05)$. For days 6-12 of extinction, a two-way repeated-measures ANOVA found a significant interaction $\left(F_{(6,54)}=2.721, P<\right.$ $0.05)$, a significant effect of time $\left(F_{(6,54)}=7.351, P<0.0001\right)$, and no effect of group $(P>0.05)$. Post-hoc LSD tests found that those rats that received ICI had more active lever presses on day 6 compared with their vehicle-control counterparts $(P<0.05)$.

The Supplemental figure shows inactive lever presses for the extinction sessions for all experiments.

\section{Histology}

Figure $4 \mathrm{~A}$ shows a representative photomicrograph of two microinjector tracks in the IL. Figure $4 \mathrm{~B}$ shows a diagram of the mPFC with the termination points of the microinjector tracks in the PL and the points of 20 randomly selected rats' microinjection sites in the IL. Due to the large number of IL microinjections, only 20 sites are depicted in Figure 4B to avoid the lack of clear injection sites that would have resulted from depicting all termination points.

\section{Discussion}

The present findings indicate that the IL regulates the consolidation of extinction of cocaine-seeking behavior and add to a growing body of evidence strongly implicating the IL as a critical locus for the inhibition of learned behavior induced via extinction training. Early work using IL lesions suggested that rats with such lesions had impaired extinction of fear conditioning (Morgan et al. 1993). Since then, evidence has accumulated indicating that the IL is involved in the extinction of a variety of tasks including cued fear conditioning (Quirk et al. 2000; Morgan et al. 2003), Pavlovian appetitive conditioning (Rhodes and Killcross 2004), and trace eye-blink conditioning (Weible et al. 2000). In particular, it appears that the IL is critically involved in the consolidation of extinction (SierraMercado et al. 2006; Quirk and Mueller 2008). The present findings add an important dimension to the literature as they demonstrate that the IL regulates the consolidation of extinction following the instrumental learning task of cocaine self-administration. The current results, together with those showing that IL activity is necessary for the expression of extinction of drug-seeking (Peters et al. 2008) and the extinction of fear conditioning (Sierra-Mercado et al. 2006), suggest that the IL may serve as a critical locus of memories for inhibiting learned behaviors. Moreover, the present findings provide a paradigm for investigating the memory consolidation underlying the extinction of cocaine selfadministration. The use of post-training manipulations to influence memory is particularly important, as affecting normal IL activity would be expected to influence the animal's behavior during the extinction session (Peters et al. 2008).

In the present study, $\mathrm{BM}$ microinjections into the IL impaired rats' retention when given after 30-min extinction sessions, suggesting that IL inactivation immediately after the session impaired memory consolidation of the extinction learning. Control experiments showed that the impaired retention was not due to spread of BM to the PL or due to continued effects of $\mathrm{BM}$ on the subsequent extinction session. In contrast, posttraining activation of IL AMPA receptors by the allosteric AMPA receptor potentiator PEPA enhanced retention of the extinction learning. This enhancement was apparent during the short (15-min) extinction sessions on days 1-5 and the 2-h extinction sessions on days 6-12. This finding is consistent with previous work showing that systemic and intra-mPFC administration of PEPA to mice enhances the extinction of fear conditioning (Zushida et al. 2007). The current findings also provide evidence for the ability to enhance extinction after cocaine selfadministration using the present paradigm, an issue of particular importance for the study of drug addiction.

\section{$\beta$-adrenergic receptors}

Previous work has identified the noradrenergic system, and particularly the $\beta$-adrenergic receptors, as playing a critical role in memory consolidation (McGaugh 2000). Lesions of the locus coeruleus noradrenergic projections, which provide the noradrenergic 

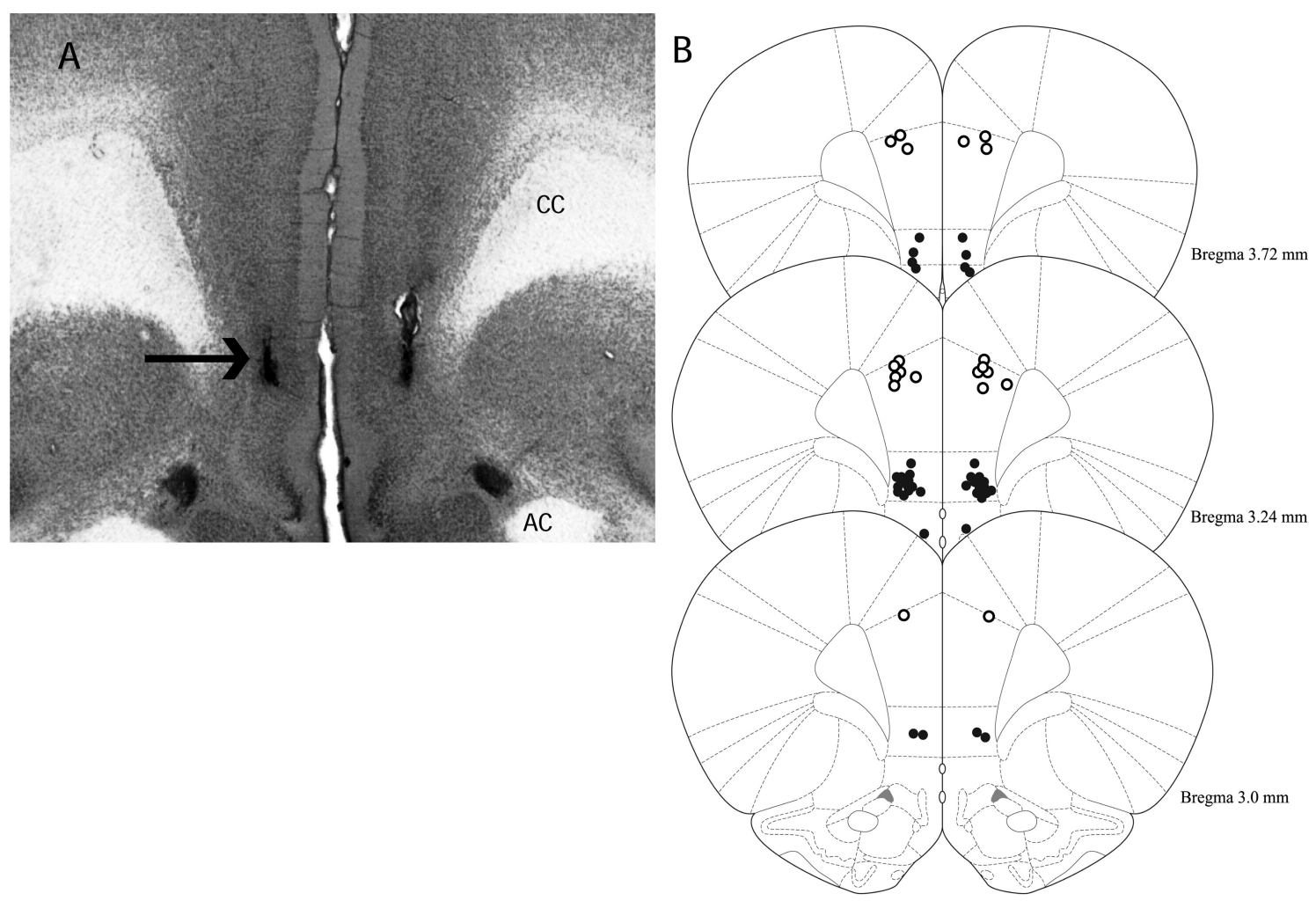

Figure 4. (A) Representative photomicrograph of microinjector tracks terminating in the IL. (Arrow) Needle track terminating in the IL. (CC) Corpus callosum, (AC) anterior commissure. (B) Diagrams showing the microinjector tracks terminating in the PL $(O)$ and 20 randomly selected rats' needle track termination points in the IL (•). A/P coordinates (in millimeters) are given relative to bregma. (Figures adapted from Paxinos and Watson [2005] and reprinted with permission from Elsevier $\mathbb{C} 2005)$.

input to the forebrain, impair the extinction of active avoidance with little to no effect on the acquisition or retention of the original learning (Fibiger and Mason 1978; Mason and Fibiger 1979). Mueller et al. (2008) found that IL blockade of $\beta$-adrenergic receptors impairs the retention of extinction of tone fear conditioning. Consistent with the previous work, the present experiments found that intra-IL microinjections of a $\beta_{2}$-adrenergic agonist or antagonist enhanced or impaired retention, respectively, of extinction for cocaine self-administration. In the current experiments, pre-training, but not post-training, microinjections of the $\beta_{2}$-adrenergic antagonist into the IL impaired retention. With the pre-training administration, there were no obvious effects of the drug on rat behavior during the session, suggesting that the impaired retention was due to effects on memory consolidation. This finding suggests that the release of norepinephrine and subsequent activation of the $\beta_{2}$-adrenergic receptors were limited to the period of the extinction session itself and that no $\beta_{2}$-adrenergic receptor activation of any consequence occurred in the period after the extinction session. The lack of effect of the post-training antagonist is consistent with those of Mueller et al. (2008) in which pre-training, but not post-training, $\beta$-adrenergic receptor blockade in the IL impaired retention of the fear conditioning extinction. In contrast, post-training $\beta_{2}$-adrenergic receptor activation by clenbuterol enhanced retention presumably because such activation was additive to the $\beta_{2}$-adrenergic receptor stimulation during the session itself.

Evidence suggests that norepinephrine applied to the IL increases the overall firing rate of IL pyramidal neurons (Mueller et al. 2008). Although few studies have examined $\beta$-adrenergic receptors in the IL, $\beta_{2}$-adrenergic receptors may be located presynaptically in the IL, as autoradiography (Rainbow et al.
1984; Booze et al. 1989), but not in situ hybridization studies (Nicholas et al. 1993), found such receptors in the mPFC. Evidence from the hypothalamus suggests that presynaptically located $\beta_{2}$ receptors are located on incoming glutamatergic neurons and positively modulate glutamate release (Lee et al. 2007). Whether $\beta_{2}$ receptors have a similar role in IL circuitry in the present paradigm is unknown. However, such a mechanism would be consistent with the present results that post-training activation of glutamatergic AMPA receptors in the IL enhances retention of extinction.

\section{Methodological considerations}

The choice of using shortened sessions was influenced by considerable evidence showing that manipulations become increasingly ineffective in affecting memory consolidation when the time between the learning event and the manipulation increases (Duncan 1949; McGaugh 1966), and evidence indicates that IL consolidation of extinction learning is finished by $2 \mathrm{~h}$ after the training (Burgos-Robles et al. 2007). The shortened sessions, therefore, permitted the pharmacological manipulation to be temporally closer to a greater proportion of the learning and thereby have a greater effect on the consolidation than would be expected with a full-length session.

When administered after 30-min sessions, BM impaired retention, but this impairment was not visible until the rats returned on day 6 for a full 2-h session. The lack of effect by most of the present experimental manipulations (the PEPA experiment being the exception) on days $2-5$ is surprising. The lack of effect stands in contrast to findings from fear conditioning in which manipulations influence the retention of extinction 
following only $1 \mathrm{~d}$ of extinction training (Sierra-Mercado et al. 2006; Mueller et al. 2008), though the differences between extinction of a Pavlovian task and extinction of the instrumental task of cocaine self-administration are significant. One possible explanation for the findings is that the microinjections affected the rats' encoding of time or some aspect of time. However, in all the experiments, neither the vehicle nor drug groups were exposed to extinction sessions longer than 30 min until day 6 . Thus, it is not clear what aspect of time encoding could have been enhanced or impaired in the respective experiments. More likely, the various manipulations influenced the retention of each day's learning. However, except in the PEPA experiment, the differences were not large enough to be measured in the shortened session. Several possibilities may explain why such differences were not large enough. Typically, even after extended extinction training, rats that have undergone cocaine self-administration press the active lever several times at the beginning of the session in a "sampling" phenomenon, presumably to determine whether any drug reinforcement is present that day. Thus, in a shortened extinction session, such sampling would be responsible for much of the active lever pressing, regardless of any manipulations administered on prior days. Second, the shortened extinction sessions produced considerable day-to-day variability in individual animals, decreasing the likelihood for quantifying an impairment or enhancement. Third, if substantial consolidation has already occurred prior to the manipulations (more likely in the 30-min session than the 15-min sessions), it would be more difficult to impair or enhance this consolidation dramatically enough to be observable in a shortened session, particularly when the number of lever presses during a shortened session is already low. One, or a combination, of these factors may explain why group differences were more apparent on days 6-12 where the extinction sessions were $2 \mathrm{~h}$ long.

\section{Interactions with other structures}

The present data do not demonstrate whether the IL stores memories or modulates their consolidation or whether it interacts with other structures during the consolidation process. Previous findings indicate that IL activity is necessary for the expression of extinction after cocaine self-administration (Peters et al. 2008), which along with the current results suggests that the IL may be a critical site of consolidation and storage of extinction memories for cocaine self-administration. Such findings are consistent with those examining tone fear conditioning extinction where activity in the IL during extinction affects the consolidation of the extinction learning (Sierra-Mercado et al. 2006; Burgos-Robles et al. 2007; Mueller et al. 2008), and appears to be critical for the expression of the extinction memory on later tests (Vidal-Gonzalez et al. 2006). In the tone fear conditioning paradigm, the IL is believed to suppress the freezing response to the tone via projections to the intercalated cells of the basolateral amygdala, which, in turn, regulate central amygdala control of freezing (Quirk and Mueller 2008). In contrast, drug-seeking behavior appears to be mediated via prefrontal cortical projections to the nucleus accumbens (McFarland et al. 2003, 2004; Feltenstein and See 2008; LaLumiere and Kalivas 2008). Consistent with that, prior work suggests that the IL and nucleus accumbens shell interact to suppress cocaine-seeking after extinction training (Peters et al. 2008), but it is not known whether the shell, like the IL, is also involved in the consolidation of extinction. The shell may simply be a critical output for the IL during the expression of extinction. In fact, the role of the shell in drug-seeking remains controversial, as other studies indicate that the shell promotes drug-seeking (Anderson et al. 2003, 2006). Other structures, however, must be involved in mediating critical information to the IL. Evidence suggests that a shift in context prevents the expression of previously acquired extinction after cocaine self-administration (Fuchs et al. 2005). Thus, it seems likely that hippocampal activity, perhaps via interactions with the IL, is important during the consolidation of extinction for cocaine-seeking.

\section{Conclusions}

The present experiments provide evidence that the IL regulates the consolidation of extinction learning for cocaine self-administration, indicating that this region may be generally involved in the extinction of a variety of types of learning. Moreover, these results demonstrate an experimental protocol for the investigation of extinction of cocaine self-administration that enables experimental manipulations to affect consolidation without interfering with the expression of the drug-seeking.

\section{Materials and Methods}

\section{Subjects}

Male Sprague-Dawley rats ( $\sim 300 \mathrm{~g}$ at the time of surgery, Charles River Laboratory [Wilmington, MA], $n=140$ ) were used in this study. They were individually housed, maintained in a temperature-controlled environment $\left(22^{\circ} \mathrm{C}\right)$ on a 12-h light/dark cycle (lights on at 07:00 h) with food and water ad libitum, and given $6-7 \mathrm{~d}$ to acclimatize to the vivarium before undergoing surgery. Behavioral procedures began 5-6 d after surgery. All methods used were in compliance with NIH guidelines for care of laboratory animals and were approved by the Medical University of South Carolina Institutional Animal Care and Use Committee.

\section{Surgery}

The rats were anesthetized with ketamine $\mathrm{HCl}(87.5 \mathrm{mg} / \mathrm{kg}$, i.m.) and xylazine (5 mg/kg, i.m.). Ketorolac (3 mg/kg, i.p.) was administered prior to surgery to provide analgesia. For catheter implantation, a guide cannula (22 ga, C313G; Plastics One, Inc.) was bent at a $90^{\circ}$ angle and attached to Silastic tubing (0.025 inner diameter, 0.047 outer diameter; Bio-Sil; Bio-Rad) via superglue. It was then attached to Prolite mesh via dental cement. The catheter was implanted subcutaneously between the shoulder blades and exited the skin via a dermal biopsy hole $(3 \mathrm{~mm})$. The other end of the tube was threaded under the skin above the shoulders and into the jugular vein.

The rats were then placed in a small-animal stereotaxic instrument (Kopf Instruments). Three surgical screws were implanted into the skull as anchors and guide cannulae were implanted and secured with dental cement. The nose bar was maintained at $-3.5 \mathrm{~mm}$ relative to the interaural line. A single double-barreled cannula (26 ga; Plastics One) was implanted, aimed at the prefrontal cortex bilaterally (AP: $+3.2 \mathrm{~mm}$, ML: $\pm 0.6 \mathrm{~mm}$ for each cannula, and DV: $-2.8 \mathrm{~mm}$ ) (Paxinos and Watson 2005). Whether microinjections were made into the IL or PL was determined by the length of the microinjector (see Microinjection procedures section below). After surgery, the rats were retained in an incubation chamber until they recovered from the anesthesia. Obdurators were placed in all cannulae and maintained throughout the experiments. The rats were then returned to their home cages and checked on the days following surgery to ensure that their wounds healed. Rats were flushed with heparinized cefazolin via the catheter for $7 \mathrm{~d}$ following surgery and then heparin alone throughout the remaining self-administration.

\section{Self-administration, extinction, and reinstatement procedures}

All self-administration experiments occurred in standard operant chambers with two retractable levers, a house light, and a cue light and tone-generator (Med Associates). Prior to drug selfadministration, all rats were food-deprived for $24 \mathrm{~h}$ and then 
underwent a single 15-h food-training session in which the rats were trained to press the active lever (the right lever) for a single food pellet ( $45 \mathrm{mg}$, Noyes) on a fixed-ratio 1 (FR1) schedule. Following that training, the rats were given a limited quantity of food ( $20 \mathrm{~g}$ ) immediately after every self-administration session. One day after the food training, the rats began cocaine selfadministration, and each session lasted $2 \mathrm{~h}$ or until the rats had taken a maximum of 200 infusions (one session/day). The selfadministration program was an FR1 schedule with a 20-sec timeout to prevent overdose, although the animal could still press the active lever during the timeout. All active lever presses, including those during the timeout, were recorded and are reported as "active lever presses." Each active lever press, except during the timeout, produced a $0.05-\mathrm{mL}$ infusion of $200 \mu \mathrm{g}$ of cocaine (dissolved in $0.9 \%$ sterile saline; cocaine kindly provided by National Institute on Drug Abuse [NIDA]). After 12 d of selfadministration, rats began extinction training (one session/day). Any rats whose catheters failed, did not show preference for the active lever over the last $3 \mathrm{~d}$ of self-administration, or did not take at least 10 infusions/day for 10 of the $12 \mathrm{~d}$ of selfadministration, including the last $3 \mathrm{~d}$ of self-administration, were excluded from the experiments $(n=35)$. During extinction training, active lever presses produced no drug infusion. Microinjections were administered on the first $5 \mathrm{~d}$ of extinction training (details given in the individual experiments below). Because the extinction of drug-seeking behavior requires considerably more time than the extinction of other tasks such as fear conditioning, $5 \mathrm{~d}$ of microinjections was chosen to maximize the likelihood of influencing the consolidation of the extinction learning.

\section{Microinjection procedures}

Double-barreled injector needles (33 ga) were connected to PE20 tubing, which was attached to $10-\mu \mathrm{L}$ Hamilton syringes controlled by an infusion pump. The tubing was first filled with water. A small air bubble was then pulled in and then the appropriate drug solution was pulled in. The needles extended $3 \mathrm{~mm}$ beyond the end of the cannulas (for IL) or $1 \mathrm{~mm}$ beyond the end of the cannulas (for PL). All microinjections $(0.3 \mu \mathrm{L})$ occurred over 60 $\mathrm{sec}$, and the injector needles were left in place for an additional $60 \mathrm{sec}$ to allow for diffusion from the site of the injection.

\section{Experiment 1}

On days 1-5 of extinction, rats received microinjections of artificial cerebrospinal fluid (aCSF; vehicle) or the GABA-B and -A agonists baclofen and muscimol (BM, 1 and $0.1 \mathrm{mM}$, respectively) into the IL immediately after each session. The extinction session on days $1-5$ of extinction were 30 min in length, whereas those on days 6-12 were $2 \mathrm{~h}$ in length. In order to control for possible spread of BM into the PL being responsible for the effects, rats underwent identical extinction training but received microinjections into the PL immediately after the 30-min extinction sessions on days 1-5. As it was possible that the BM effects were on the rats' behavior during subsequent sessions rather than on the consolidation of the previous session, in a control experiment, rats underwent extinction training and received the microinjections of aCSF or BM into the IL $3 \mathrm{~h}$ after the cessation of the extinction session on days $1-5$.

\section{Experiment 2}

Rats underwent extinction training in which the sessions on the first $5 \mathrm{~d}$ of extinction were $15 \mathrm{~min}$ in length. The length of session was chosen based on the results from Experiment 1, in which 30-min sessions produced considerable extinction by day 6 of extinction training, making it difficult for memory enhancement to occur. Thus, 15-min sessions were chosen for this experiment. Immediately after each session, rats received intra-IL microinjections of either vehicle (90\% aCSF, 10\% DMSO) or PEPA (30 ng/ side). PEPA is an allosteric AMPA receptor potentiator that reduces the rate of desensitization of the AMPA receptor (Sekiguchi et al. 1997, 1998).

\section{Experiment 3}

Rats underwent extinction training in which the sessions on the first $5 \mathrm{~d}$ of extinction were $15 \mathrm{~min}$ in length. Immediately after each session, rats received intra-IL microinjections of either aCSF or the $\beta_{2}$-adrenergic agonist clenbuterol (3 or $10 \mathrm{ng}$ ). Following the first $5 \mathrm{~d}$ of extinction, rats continued with 2 -h extinction sessions with no microinjections.

\section{Experiment 4}

Rats underwent extinction training in which the sessions on the first $5 \mathrm{~d}$ of extinction were $30 \mathrm{~min}$ in length. In the first part of Experiment 4, rats received intra-IL microinjections of either aCSF or the $\beta_{2}$-adrenergic antagonist ICI ( $\left.1 \mathrm{nmol} / \mathrm{side}\right)$ immediately after each extinction session on extinction days 1-5. Following the first $5 \mathrm{~d}$ of extinction, rats continued with 2 -h extinction sessions with no microinjections. In the second part of Experiment 4, rats received intra-IL microinjections of either aCSF or ICI immediately before each extinction session on extinction days $1-5$. Following the first $5 \mathrm{~d}$ of extinction, rats continued with 2 -h extinction sessions with no microinjections.

\section{Histology and statistics}

Rats were overdosed with sodium pentobarbital (100 mg/kg, i.p.) and intracardially perfused with $0.9 \%$ saline. The brains were removed and stored in 10\% formalin for at least $24 \mathrm{~h}$. Coronal sections $(100 \mu \mathrm{m}$ thick) were made using a vibratome. Sections were mounted on gel-coated slides and then stained with cresyl violet. Sites of injector needles were verified with a light microscope, and only those rats with needle tracks terminating in the appropriate structure were included in the final analysis. As evidence indicates that the dorsal peduncular cortex, which lies immediately ventral to the IL, is also part of the ventromedial PFC that regulates the extinction learning (Peters et al. 2009), rats with microinjector tips in the dorsal peduncular were included in the final analysis.

The extinction data for days $1-5$ and days 6-12 were separately analyzed using two-way repeated-measures ANOVA. Post-hoc LSD tests were used to determine the source of significant differences between the groups.

\section{Acknowledgements}

This research was supported by NIH grant USPHS DA027055 (R.T.L.) and NIH grants USPHS DA12513 and DA015369 (P.W.K.). We thank Dr. Joyce Nicholas, Kyle Smith, Jay Hutson, Karen Corson, Kellie Osborne, Ashley Clune, Kelly Bramhall, Mary Shaw, and Louisa Young for their excellent assistance.

\section{References}

Anderson SM, Bari AA, Pierce RC. 2003. Administration of the D1-like dopamine receptor antagonist SCH-23390 into the medial nucleus accumbens shell attenuates cocaine priming-induced reinstatement of drug-seeking behavior in rats. Psychopharmacology (Berl) 168: $132-138$.

Anderson SM, Schmidt HD, Pierce RC. 2006. Administration of the D2 dopamine receptor antagonist sulpiride into the shell, but not the core, of the nucleus accumbens attenuates cocaine priming-induced reinstatement of drug seeking. Neuropsychopharmacology 31: $1452-1461$.

Booze RM, Crisostomo EA, Davis JN. 1989. Species differences in the localization and number of CNS beta adrenergic receptors: Rat versus guinea pig. J Pharmacol Exp Ther 249: 911-920.

Burgos-Robles A, Vidal-Gonzalez I, Santini E, Quirk GJ. 2007. Consolidation of fear extinction requires NMDA receptor-dependent bursting in the ventromedial prefrontal cortex. Neuron 53: 871-880.

Burgos-Robles A, Vidal-Gonzalez I, Quirk GJ. 2009. Sustained conditioned responses in prelimbic prefrontal neurons are correlated with fear expression and extinction failure. J Neurosci 29: 8474-8482.

Duncan CP. 1949. The retroactive effect of electroshock on learning. J Comp Physiol Psychol 42: 32-44. 
Feltenstein MW, See RE. 2008. The neurocircuitry of addiction: An overview. Br J Pharmacol 154: 261-274.

Fibiger HC, Mason ST. 1978. The effects of dorsal bundle injections of 6-hydroxydopamine on avoidance responding in rats. $\mathrm{Br} J$ Pharmacol 64: 601-605.

Fuchs RA, Evans KA, Ledford CC, Parker MP, Case JM, Mehta RH, See RE. 2005. The role of the dorsomedial prefrontal cortex, basolateral amygdala, and dorsal hippocampus in contextual reinstatement of cocaine seeking in rats. Neuropsychopharmacology 30: 296-309.

LaLumiere RT, Kalivas PW. 2008. Glutamate release in the nucleus accumbens core is necessary for heroin seeking. J Neurosci 28: $3170-3177$

Lebron K, Milad MR, Quirk GJ. 2004. Delayed recall of fear extinction in rats with lesions of ventral medial prefrontal cortex. Learn Mem 11: $544-548$.

Lee JG, Choi IS, Park EJ, Cho JH, Lee MG, Choi BJ, Jang IS. 2007. $\beta_{2}$-adrenoceptor-mediated facilitation of glutamatergic transmission in rat ventromedial hypothalamic neurons. Neuroscience 144: 1255-1265.

Mason ST, Fibiger HC. 1979. Noradrenaline and avoidance learning in the rat. Brain Res 161: 321-333.

McFarland K, Kalivas PW. 2001. The circuitry mediating cocaine-induced reinstatement of drug-seeking behavior. J Neurosci 21: 8655-8663.

McFarland K, Lapish CC, Kalivas PW. 2003. Prefrontal glutamate release into the core of the nucleus accumbens mediates cocaine-induced reinstatement of drug-seeking behavior. J Neurosci 23: 3531-3537.

McFarland K, Davidge SB, Lapish CC, Kalivas PW. 2004. Limbic and motor circuitry underlying footshock-induced reinstatement of cocaine-seeking behavior. J Neurosci 24: 1551-1560.

McGaugh JL. 1966. Time-dependent processes in memory storage. Science 153: $1351-1358$.

McGaugh JL. 2000. Memory-a century of consolidation. Science 287: $248-251$.

McLaughlin J, See RE. 2003. Selective inactivation of the dorsomedial prefrontal cortex and the basolateral amygdala attenuates conditioned-cued reinstatement of extinguished cocaine-seeking behavior in rats. Psychopharmacology (Berl) 168: 57-65.

Milad MR, Quirk GJ. 2002. Neurons in medial prefrontal cortex signal memory for fear extinction. Nature 420: $70-74$.

Morgan MA, Romanski LM, LeDoux JE. 1993. Extinction of emotional learning: Contribution of medial prefrontal cortex. Neurosci Lett 163: $109-113$.

Morgan MA, Schulkin J, LeDoux JE. 2003. Ventral medial prefrontal cortex and emotional perseveration: The memory for prior extinction training. Behav Brain Res 146: $121-130$.

Mueller D, Porter JT, Quirk GJ. 2008. Noradrenergic signaling in infralimbic cortex increases cell excitability and strengthens memory for fear extinction. J Neurosci 28: 369-375.

Nicholas AP, Pieribone VA, Hokfelt T. 1993. Cellular localization of messenger RNA for $\beta-1$ and $\beta-2$ adrenergic receptors in rat brain: An in situ hybridization study. Neuroscience 56: 1023-1039.

Park WK, Bari AA, Jey AR, Anderson SM, Spealman RD, Rowlett JK, Pierce RC. 2002. Cocaine administered into the medial prefrontal cortex reinstates cocaine-seeking behavior by increasing AMPA receptor-mediated glutamate transmission in the nucleus accumbens. J Neurosci 22: 2916-2925.
Paxinos G, Watson C. 2005. The rat brain in stereotaxic coordinates. Elsevier, Amsterdam, The Netherlands.

Peters J, Kalivas PW, Quirk GJ. 2009. Extinction circuits for fear and addiction overlap in prefrontal cortex. Learn Mem 16: 279-288.

Peters J, LaLumiere RT, Kalivas PW. 2008. Infralimbic prefrontal cortex is responsible for inhibiting cocaine seeking in extinguished rats. J Neurosci 28: 6046-6053.

Quirk GJ, Mueller D. 2008. Neural mechanisms of extinction learning and retrieval. Neuropsychopharmacology 33: 56-72.

Quirk GJ, Russo GK, Barron JL, Lebron K. 2000. The role of ventromedial prefrontal cortex in the recovery of extinguished fear. J Neurosci 20: $6225-6231$.

Rainbow TC, Parsons B, Wolfe BB. 1984. Quantitative autoradiography of $\beta 1$ - and $\beta 2$-adrenergic receptors in rat brain. Proc Natl Acad Sci USA 81: $1585-1589$.

Rebec GV, Sun W. 2005. Neuronal substrates of relapse to cocaine-seeking behavior: Role of prefrontal cortex. J Exp Anal Behav 84: $653-666$

Rhodes SE, Killcross AS. 2007. Lesions of rat infralimbic cortex enhance renewal of extinguished appetitive Pavlovian responding. Eur J Neurosci 25: $2498-2503$.

Rhodes SE, Killcross S. 2004. Lesions of rat infralimbic cortex enhance recovery and reinstatement of an appetitive Pavlovian response. Learn Mem 11: 611-616.

Rogers JL, Ghee S, See RE. 2008. The neural circuitry underlying reinstatement of heroin-seeking behavior in an animal model of relapse. Neuroscience 151: 579-588.

Santini E, Quirk GJ, Porter JT. 2008. Fear conditioning and extinction differentially modify the intrinsic excitability of infralimbic neurons. J Neurosci 28: 4028-4036.

Sekiguchi M, Fleck MW, Mayer ML, Takeo J, Chiba Y, Yamashita S, Wada K. 1997. A novel allosteric potentiator of AMPA receptors: 4-2-(phenylsulfonylamino)ethylthio-2,6-difluoro-phenoxycetamide. J Neurosci 17: 5760-5771.

Sekiguchi M, Takeo J, Harada T, Morimoto T, Kudo Y, Yamashita S, Kohsaka S, Wada K. 1998. Pharmacological detection of AMPA receptor heterogeneity by use of two allosteric potentiators in rat hippocampal cultures. Br J Pharmacol 123: 1294-1303.

Sierra-Mercado D, Jr., Corcoran KA, Lebron-Milad K, Quirk GJ. 2006. Inactivation of the ventromedial prefrontal cortex reduces expression of conditioned fear and impairs subsequent recall of extinction. Eur J Neurosci 24: 1751-1758.

Vidal-Gonzalez I, Vidal-Gonzalez B, Rauch SL, Quirk GJ. 2006. Microstimulation reveals opposing influences of prelimbic and infralimbic cortex on the expression of conditioned fear. Learn Mem 13: $728-733$.

Weible AP, McEchron MD, Disterhoft JF. 2000. Cortical involvement in acquisition and extinction of trace eyeblink conditioning. Behav Neurosci 114: 1058-1067.

Zushida K, Sakurai M, Wada K, Sekiguchi M. 2007. Facilitation of extinction learning for contextual fear memory by PEPA: A potentiator of AMPA receptors. J Neurosci 27: 158-166.

Received August 4, 2009; accepted in revised form February 3, 2010. 


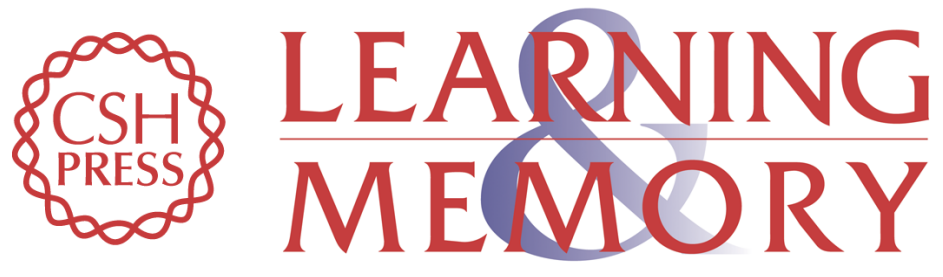

\section{The infralimbic cortex regulates the consolidation of extinction after cocaine self-administration}

Ryan T. LaLumiere, Kate E. Niehoff and Peter W. Kalivas

Learn. Mem. 2010, 17:

Access the most recent version at doi:10.1101//m.1576810

Supplemental
Material http://learnmem.cshlp.org/content/suppl/2010/03/29/17.4.168.DC1

References This article cites 41 articles, 20 of which can be accessed free at: http://learnmem.cshlp.org/content/17/4/168.full.html\#ref-list-1

License

Email Alerting Receive free email alerts when new articles cite this article - sign up in the box at the Service top right corner of the article or click here. 